\title{
Localizando o espaço público: Gentrification e cultura urbana
}

Localising Public Space: Gentrification and Urban Culture

Localisant l'espace public: Gentrification et culture urbaine

\section{Rogério Proença Leite}

\section{OpenEdition}

\section{Journals}

Edição electrónica

URL: http://journals.openedition.org/rccs/436

DOI: $10.4000 /$ rccs. 436

ISSN: 2182-7435

\section{Editora}

Centro de Estudos Sociais da Universidade de Coimbra

Edição impressa

Data de publição: 1 Dezembro 2008

Paginação: 35-54

ISSN: 0254-1106

\section{Refêrencia eletrónica}

Rogério Proença Leite, «Localizando o espaço público: Gentrification e cultura urbana », Revista Crítica de Ciências Sociais [Online], 83 | 2008, colocado online no dia 01 dezembro 2012, criado a 30 abril 2019. URL : http://journals.openedition.org/rccs/436 ; DOI : 10.4000/rccs.436

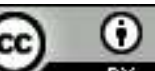




\section{ROGÉRIO PROENÇA LEITE}

\section{Localizando o espaço público: Gentrification e cultura urbana*}

O artigo discute a noção de espaço público, tomando como referente um estudo de caso sobre as políticas de requalificação urbana e gentrification no Recife, Brasil. A partir do estudo de caso, o autor problematiza o modo como nos usos do espaço (urbano) se confrontam concepções e práticas diversas de relação com o espaço público, atendendo em particular às tensões que emergem nas ressignificações que os processos de requalificação arrastam consigo. A análise do caso, centrada nos modos diversos e conflituantes como, nesse quadro, o espaço público se constitui como espaço de comunicação e cidadania, sustenta uma discussão teórica em torno da noção de espaço público, problematizada no seu duplo sentido: de esfera pública da comunicação e participação e de espaço físico de acesso e uso público.

Palavras-chave: espaço público, revitalização urbana, cidade, contra-usos do espaço.

Atendendo ao modo pelo qual se assinala a morte da vida pública na experiência social contemporânea parece, de fato, que a discussão sobre o espaço público poderia ser descrita como uma literature of loss (Kilian, 1998). No entanto, pode ser ainda oportuno refazer os caminhos de uma distinção conceitual sobre a natureza dos espaços sobre os quais se fala, quando se pretende anunciar o declínio da vida pública. A falsa sinonímia criada entre os termos espaço urbano, esfera pública e espaço público é, em parte, responsável pelo generalizado obituário que permeia a discussão contemporânea sobre cidades e vida urbana. Principalmente quando se analisam os processos mais recentes do chamado marketing urbano, fica patente a necessidade de operar distinções que possam explicar o caráter fragmentário do espaço urbano e - ainda assim - a permanência de uma vida pública, mesmo que marcada sobremaneira por práticas sociais que pulverizam a cidade em diversas "territórios de subjetivação" (Guattari, 1985).

* Uma versão mais longa e desenvolvida do argumento apresentado aqui pode ser encontrada em Leite (2007). 
Tendo como referente empírico o processo de "revitalização" urbana do Bairro do Recife Antigo, Pernambuco, Brasil, analiso aqui: (1) como as práticas constitutivas da formação dos lugares no espaço urbano incidem sobre a formação do espaço púbico; e (2) como esse processo pode contribuir para que se façam as necessárias distinções conceituais entre os termos espaço urbano, esfera pública e espaço público.

\section{Mapeando lugares e fronteiras: o Bairro do Recife Antigo}

O processo de gentrification ${ }^{1}$ do Bairro do Recife Antigo, iniciado nos anos 90, não foi uma experiência isolada nas práticas contemporâneas de preservação do patrimônio no Brasil. Sua implantação, contudo, tem sido interpretada como um marco de uma nova fase das políticas de patrimônio, por ter adotado um modelo misto de gestão, baseado no sistema de parcerias entre poder público e iniciativa privada, incluindo recursos da Prefeitura da Cidade do Recife, do Governo do Estado e do BID, através do PRODETUR e do Programa MinC/Monumenta. ${ }^{2}$ O Plano de Revitalização do Bairro do Recife seguiu o chamado marketing urbano, cujas práticas compreendem um conjunto de intervenções urbanas voltadas à transformação de sítios históricos degradados em áreas de entretenimento urbano e consumo cultural. Objetivando modernizar recursos potenciais para uma melhor inserção na "concorrência inter-cidades", através do uso estratégico do patrimônio, ${ }^{3}$ a mais recorrente característica dessas intervenções urbanas tem sido uma re-localização estética do passado, cujo padrão alterado de práticas que mimetizam o espaço público torna o patrimônio uma mercadoria cultural, passível de ser reapropriada pela população e pelo capital.

Essas práticas de gentrification empreendem o que se poderia chamar de “embelezamento estratégico" - termo utilizado por Walter Benjamin (1997)

\footnotetext{
${ }^{1}$ O termo gentrification (enobrecimento) é utilizado por autores como Harvey (1992), Featherstone (1995) e Smith (1996) para designar formas de empreendimentos que elegem certos espaços da cidade como centralidades e os transformam em áreas de investimentos públicos e privados. Sharon Zukin $(1995 ; 2000)$ utiliza a mesma expressão para designar a transformação dos significados de uma localidade histórica em um segmento do mercado, considerando a apropriação cultural do espaço a partir do intenso fluxo de capitais que estabelece formas de consumo visual.

${ }^{2} \mathrm{O}$ Monumenta surgiu de um acordo financeiro através de uma parceria entre o Ministério da Cultura e o Banco Inter-Americano para o Desenvolvimento - BID, assinado em Paris em Março de 1999. Na primeira etapa do acordo, o projeto $\mathrm{n}^{\circ}$. BR-0261 do Program to Preserve Urban Historical and Cultural Heritage, cuja agência executiva no Brasil era o próprio Ministério da Cultura, previa a mobilização de aproximadamente US $\$ 200$ milhões, sendo US $\$ 62.5$ do BID, US \$62.5 milhões do próprio governo brasileiro (incluindo a participação dos Estados e Municípios). 3 A "concorrência inter-cidades" se refere ao incremento das políticas de patrimônio como recurso estratégico para potencializar a expansão do mercado de captação de recursos no interior dos fluxos globais (Fortuna, 1997).
} 
para comentar as reformas urbanas de Paris, feitas por Haussmann no contexto do bonapartismo autoritário pós-1848, cujos desdobramentos europeus fizeram da Viena da Ringstrasse um ícone do liberalismo austríaco (Schorske, 1990). Mais de cem anos depois, as práticas de intervenção urbana continuam a "embelezar" estrategicamente as cidades históricas através das políticas de patrimônio cultural. Ao contrário, no entanto, de evitar barricadas, essas políticas erguem suas próprias fronteiras, quando segmentam e disciplinam certos espaços urbanos, para uso extensivo de lazer, turismo e consumo (Appadurai, 1986).

O pólo Bom Jesus, centro de irradiação de todo o processo de gentrification, tornou-se o espaço mais enobrecido do Bairro. Com a "revitalização", antigos e residuais moradores que residiam nos pavimentos superiores dos sobrados da Rua do Bom Jesus foram removidos e as velhas edificações foram reformadas: com cores berrantes, agora abrigam sofisticados pubs, restaurantes e dancing bars. $\mathrm{O}$ ar sombrio do cais do porto, em cuja bruma de pecado e perigo o bairro mergulhava, foi substituído pela abundância das luzes e pelos ruídos de festa. Jovens de classe média passaram a povoar as filas na porta das danceterias, casais ocuparam as mesas dispostas nas calçadas: o Bairro do Recife se tornou um agitado ponto de encontro, consumo e lazer. Talvez nenhum outro espaço na cidade fosse capaz de fazer convergir diferentes disputas por uma visibilidade pública. A partir das 18 horas, o trânsito passou a ser interditado nestas ruas. Cavaletes de madeira e um reforçado esquema de segurança transformavam então este trecho da cidade em um artificial boulevard. Pouco a pouco as ruas eram tomadas por pessoas, as calçadas pelas mesas dos bares e restaurantes.

O processo de "revitalização" mudou a paisagem urbana do Bairro do Recife, mas não alterou as assimetrias que demarcavam espacialmente as desigualdades sociais do lugar. Ao contrário, parece que aprofundou certas distâncias sociais, visíveis nas distintas formas de permanência temporal e espacial, que passaram a se revelar nas díspares sociabilidades que se estruturavam nos diferentes horários e locais na vida cotidiana do Bairro. Enquanto a Rua do Bom Jesus erguia seus cavaletes e tentava disciplinar os usos do espaço, as pessoas que não podiam - ou não queriam - compartilhar as atividades de consumo explícito migravam para outros espaços. Um dos "pontos de fuga" do Bairro do Recife era exatamente outro pólo que se desenvolveu à revelia do Plano de Revitalização. O chamado pólo Moeda, como já pude analisar em trabalho anterior (Leite, 2002), foi um caso de ocupação espontânea, numa área do Bairro que ainda não havia sido "revitalizada". Alguns bares, voltados para um público jovem, formavam o perfil underground do lugar, chamado muitas vezes de "Berlim Oriental". 
Havia, entretanto, um espaço no Bairro do Recife onde a disputa pública pelo reconhecimento político dos diferentes modos de pertencer à cidade ganhou maior visibilidade e eficácia: o Largo do Marco Zero, espaço de convergência e de fronteiras liminares. Local onde a "diferença se encontrava”, o Largo passou a desempenhar um papel fundamental na afirmação dialógica dos diferentes lugares e sociabilidades que se estruturavam no Bairro. É sobre ele que gostaria de me ocupar brevemente no tópico seguinte.

\section{Entre-lugar: o Largo do Marco Zero}

A ausência de uma demarcação simbólica específica fez do Largo um espaço vulnerável a apropriações díspares, contribuindo para que se tornasse um espaço de interações dissonantes, no qual as diferenças perdiam sua característica de estranheza: sua paisagem social indefinida era composta exatamente pela ambigüidade e contraste dos usos e contra-usos concomitantes de um Bairro enobrecido. A intervenção no Marco Zero condensou parte substantiva da política de gentrification implantada. Antes da reforma, o local era uma pequena pracinha com bancos de madeira, onde se podia, à sombra das suas árvores, conversar a qualquer hora do dia. O Marco Zero era um lugar de permanência, e não apenas de passagem, que evocava o porto e o próprio Bairro do Recife como nenhum outro local. De alguma forma, só se sentia que se tinha chegado ao Bairro quando se ia até à praça, onde estava a estátua do Barão do Rio Branco olhando para o mar, junto ao pequeno monumento que localizava o marco zero da cidade.

Com a reforma, a pracinha foi simplesmente arrasada: arrancaram-lhe as árvores com escavadeiras, removeram os bancos e refizeram seu traçado, que ganhou perfil de Largo. A estátua do Rio Branco foi deslocada para o lado, entre ensolaradas palmeiras imperiais. Um novo piso desenhou uma enorme rosa dos ventos no seu centro (só visível quando se sobrevoa o local), margeada pela frase: "Eu vi o mundo...ele começava no Recife" ${ }^{4} \mathrm{O}$ resultado foi a transformação de um espaço que tinha potencial para o encontro público em um espaço para espetáculos públicos. Sem bancos e sem sombra, o novo Largo do Marco Zero repetia uma experiência comum nas metrópoles brasileiras: a remoção dos utensílios urbanos que asseguravam a permanência fortuita de pessoas nos locais.

O enorme vazio do Largo, somente preenchido em dias de grandes eventos - shows que mobilizam uma massa disforme e temporária de

\footnotetext{
${ }^{4} \mathrm{O}$ desenho do piso, com a rosa dos ventos e a referida frase, foi uma concepção do artístico plástico pernambucano Cícero Dias.
} 
pessoas -, passou a ser a representação urbanista mais fiel da idéia empresarial do Plano de Revitalização do Bairro do Recife em mudar a imagem do Bairro, transformando-o em um "Espaço público para reunião e o espetáculo" (AD/DIPER, 1992). A reforma do Marco Zero teve dois objetivos fundamentais. Primeiro, imprimir no Bairro uma imagem-símbolo da própria retomada de uma área que já foi, no passado, uma das mais importantes da cidade do Recife. A reforma marcaria essa reapropriação de uma área histórica, cujo patrimônio cultural estava sendo igualmente redescoberto e revalorizado. Segundo, a reforma veio suprir uma deficiência do local: a falta de um espaço amplo para eventos de grande porte.

Inicialmente, os usos diurnos do Largo foram visivelmente prejudicados pela impossibilidade de permanência em um espaço desprovido de proteção ambiental contra as ensolaradas manhãs nordestinas. À noite, os grandes eventos de massa foram naturalmente transferidos para o Largo, que passou a abrigar a multidão sem os transtornos usuais dos outros pólos. No Largo podiam ser vistos os habituais freqüentadores do Bom Jesus, os usuários do pólo Moeda, as "liminaridades" do eixo Marquês de Olinda-Rio Branco (incluindo travestis e prostitutas), as camadas mais baixas que têm nesses eventos a sua oportunidade de freqüentar o Bairro, bandos de jovens funkeiros, turistas, famílias, pessoas mais idosas, crianças, os meninos em situação de rua, os pequenos vendedores do Bom Jesus, as catadoras de latinhas, possíveis moradores da Favela do Rato.

No amplo espaço do Largo, as sociabilidades eram marcadas pelo clima de festa. Casais dançavam, outros apenas assistiam a shows. Era comum que seus freqüentadores se misturassem com facilidade, fato que dificilmente ocorria nos outros pólos do Bairro. Em noites normais, sem a agitação dos eventos, o Largo desempenhava no Bairro do Recife o papel de manter a cidade aberta. Bem iluminado e espaçoso, embora tivesse perdido no tempo diurno as possibilidades de permanência, à noite o Largo ganhou um atributo que antes não tinha: o de ser um espaço sem fronteiras definidas, onde se podia simplesmente perambular sem o apelo do consumo do pólo enobrecido do Bom Jesus. A escala ampliada do largo imprime uma sensação de vazio e afastamento que, de certo modo, dificulta contatos mais próximos entre as pessoas, reforçando a funcionalidade eclética da organização do espaço urbano e arquitetônico haussmaniano da "Paris" pernambucana.

No Bairro do Recife, a despeito da monumentalidade do ecletismo e do enorme vazio que se formou no Largo do Marco Zero, os usos e contra-usos sociais subverteram aquele cenário enobrecido. Talvez, exatamente por ter sido transformado nesse enorme palco para eventos grandiosos de entretenimento, o Largo passou a ser alvo de manifestações sociais e políticas da 
cidade, tornando-se um dos espaços mais centrais e de maior visibilidade pública do Bairro que, por sua vez, já havia se transformando em uma centralidade do Recife. Ao abrigar atos públicos de significativa carga simbólica, o Bairro, através do seu Largo, revelava a mais contundente subversão dos seus usos: a que se estendia para além do consumo e lazer e alcançava a dimensão propriamente política da cidade. $\mathrm{O}$ antigo Bairro do Recife nunca teve uma centralidade política para manifestações públicas. O Largo do Marco Zero, da mesma forma que passou a ter uma programação de eventos variada, também abrigou atos públicos diversos, a exemplo de cultos ecumênicos anti-semitas, manifestações políticas pela paz ou passeatas pelos direitos humanos.

Os primeiros atos, manifestações e rituais públicos foram os indícios preliminares de uma contra-retomada prática e simbólica do Bairro, cujas fronteiras e usos já anunciavam que ele dificilmente se manteria como um mero espaço de consumo e lazer, socialmente asséptico e despolitizado. O Plano de Revitalização tinha como meta tornar o Bairro do Recife em um "espaço de lazer e diversão", objetivando criar um espaço que promovesse "a concentração de pessoas nas áreas públicas criando um espetáculo urbano”. Conseguiu. Mas talvez não esperasse que esse espetáculo também enveredasse para os temas políticos. Pretendeu, e da mesma forma foi bem sucedido, promover a "Recuperação da imagem do Bairro" e "Manutenção e valorização do patrimônio ambiental e cultural” (AD/DIPER, 1992). Talvez não tenha imaginado que os usos do Bairro iriam imprimir nessa imagem e em seu patrimônio significados que ultrapassariam os limites do embelezamento estratégico das políticas de gentrification. O urbanismo empresarial e sua lógica cartesiana parece esquecer que uma cidade é feita de pessoas: “(...) é preciso pensar em pessoas utilizando e transformando os espaços em que vivem. Paisagens vazias podem ser enganadoras” (Arantes, 1997a).

Talvez nenhum outro ato público pudesse ser tão fiel à idéia de contra-usos, entendida aqui para qualificar as ações deliberadas de subversão prática e/ou simbólica dos usos esperados para os espaços enobrecidos (Leite, 2007), quanto a última manifestação que aconteceu no Bairro no Recife em 2000.

A proposta de "revitalização" do Bairro do Recife foi um ponto em comum entre alguns integrantes do Partido da Frente Liberal - PFL (então considerado de direita) e o Partido do Movimento democrático Brasileiro - PMDB (então considerado de centro-esquerda). Nas eleições para Prefeito do Recife em 2000, venceu o candidato da oposição, João Paulo, do Partido dos Trabalhadores - PT. Na edição do dia 30 de Outubro de 2000, o Diário 
de Pernambuco, principal jornal da cidade do Recife, anunciava em primeira página: "RECIFE, UMA CIDADE VERMELHA". A matéria se referia fato do PT ter ido justamente ao Largo do Marco Zero comemorar a sua vitória. Em um ritual de reapropriação simbólica da cidade, os militantes e simpatizantes do partido, juntamente com o prefeito eleito, tomaram conta de todo o Bairro. Vestidos de vermelho, ao som de um trio elétrico, foi ocupada a área do Marco Zero, assim como o seu entorno, em uma esfuziante manifestação pública de retomada política de um espaço que fora reformado pelo PFL e construído como ícone de uma cidade enobrecida. Este ato público, com todas as características de uma festa do povo, foi o maior ruído visual que o Bairro poderia ter.

Com a centralidade que ganhou o Bairro, ao se transformar em um dos espaços de maior visibilidade pública da cidade, a comemoração do PT reafirmava uma tendência já observada antes: o Bairro do Recife como um todo, e em particular o Marco Zero, tornou-se um espaço voltado à publicização de diferentes visões de mundo e distintas reivindicações de validades. Como boa parte das manifestações que pretendem atribuir novos sentidos a certos espaços da cidade, a comemoração do PT foi uma forma de ritual público de construção de um espaço de significação.

\section{Lugares}

As fronteiras que demarcavam os espaços do Bairro do Recife passaram a guardar estreita relação com os usos predominantes que os qualificavam como lugares. Por lugar, entendo uma determinada demarcação física e/ou simbólica no espaço, cujos usos o qualificam e lhe atribuem sentidos convergentes, orientando ações sociais e sendo por estas delimitado reflexivamente. Um lugar seria, assim, um espaço de representação, cuja singularidade é construída pela "territorialidade subjetivada" (Guattari, 1985), mediante práticas sociais e usos semelhantes. No Bairro do Recife, apesar da existência de usos diversificados e representações dissonantes sobre cada um dos seus espaços, havia uma convergência de sentidos em cada um deles: a Rua do Bom Jesus era tipicamente um lugar de consumo (pelas predominância das práticas de entretenimento), a Rua da Moeda um lugar de fuga e refúgio (pela característica de abrigar os excluídos dos pólos de animação), a Favela do Rato um lugar predominantemente de refúgio e morada (por se constituir em um espaço de residência vernacular).

Lugares urbanos têm fronteiras, mas elas não são necessariamente fixas e muito menos dadas: são construídas socialmente e negociadas cotidianamente com outros lugares no complexo processo de interação pública, através do qual afirmam suas singularidades, emergem conflitos, dissensões 
e, eventualmente, consensos. Uma convergência de sentidos é assim, condição necessária para que se "pratique" um espaço e o transforme em lugar, e essa convergência não implica, necessariamente, consenso, mas antes possibilidade de entendimento. Em termos genéricos, poderíamos dizer que o consenso se refere ao produto final de uma interação racional. O que chamo aqui de possibilidade de entendimento, ao contrário, é antes o próprio processo constitutivo de convergência de sentidos. Para que haja sentidos compartilhados, é necessário que ocorra um entendimento mínimo sobre o que representa um lugar e sobre os códigos culturais que o qualificam.

Essa convergência de sentidos é necessária tanto quanto o são as relações de continuidade espaço-temporal. Se as ações interativas incidem e são reflexivamente delimitadas pelos lugares, não basta que eles existam como "eventos". Ainda que possam ser cambiantes (Augé, 1994), terem fronteiras entrecortadas e flexíveis (Arantes, 2000), serem traspassados pelos "espaços de fluxos" (Castells, 1999), articularem de modo dissonante usos e contrausos, poderem ser híbridos e fragmentários, os lugares guardam certos vínculos mais perenes da vida social. É através deles que interesses se tornam convergentes, códigos de conduta são redesenhados, marcas corporais são inscritas e reconhecidas, nexos são refeitos entre identidade e espaços urbanos. Essa continuidade espaço-temporal, entretanto, não deve confundir os lugares que se estruturam na experiência urbana contemporânea com configurações rígidas e bem definidas, como são os chamados "lugares antropológicos" (Gupta e Ferguson, 1992). Embora continuem a ser identitários, esses lugares (pós)modernos podem ser efêmeros, mas, enquanto se mantêm, devem apresentar possibilidades mínimas de continuidade. O que pode ser uma característica singular dos lugares urbanos é o diversificado conteúdo em torno do qual ocorre o que estou chamando de convergência de sentidos. A diversificação simbólica resulta na polissemia do espaço qualificado como lugar, cujo espectro permite que um mesmo espaço seja configurado de modo híbrido como diferentes lugares. O Bairro do Recife, como um todo, é um exemplo dessa compartimentada e compartilhada existência híbrida de diferentes lugares, assim como a própria Rua do Bom Jesus, cujos usos e contra-usos atribuíam sentidos diferentes e faziam representações distintas sobre um mesmo espaço qualificado como lugar. Os lugares podem, ainda, apresentar conjuntos de sentidos convergentes diversos, através dos quais é possível ocorrer o entendimento cultural necessário para que sejam estabelecidas uma ou mais identidades socioespaciais. Se híbrido, um lugar é sempre um campo tenso de disputas e negociações. Se fragmentário, a afirmação da diferença se dispersa em distintas configurações espaciais. Em ambos os casos, a demarcação espacial 
de um lugar implica em zonas de fronteiras, escalas sobrepostas, áreas liminares, interstícios.

A coexistência dos lugares em situações de espaço compartilhado, como no caso do Bairro insular do Recife Antigo, induz a contextos que tendem para a necessária formação de espaços públicos. Uma vez que não existem por si mesmos, mas se estruturam internamente através de experiências e subjetividades compartilhadas, os lugares mantêm sua singularidade e integridade identitária mediante a contraposição. Em outras palavras, embora signifiquem uma demarcação socioespacial que estria os espaços da cidade, eles precisam se contrapor a outros lugares, na afirmação pública do reconhecimento e da sua própria existência e singularidade. Esses lugares, mais do que desejarem ser representados, como sugere Martín-Barbero, demandam ser reconbecidos: “(...) tornar-se visíveis socialmente, em sua diferença" (Martín-Barbero, 2000: 45). As disputas, que incidem sobre as demarcações socioespaciais urbanas e desfazem as condições de entendimento na direção da busca pelo reconbecimento, podem resultar tanto em um enfrentamento político mais elaborado, quanto na mera contraposição de estilos de vida, marcados pelas formas cotidianas de ritualizar códigos de conduta. Em ambos os casos são estabelecidas as bases políticas dos usos públicos dos espaços da cidade.

A confluência entre as sociabilidades comunitárias e seus lugares não apenas é necessária - para afirmar publicamente as diferenças que precisam ser reconhecidas (Martín-Barbero, 2000) -, como imprescindível para a própria demarcação socioespacial dos lugares. A forma binária e contrastiva subsiste (pertencer ou não pertencer; partilhar ou não partilhar) como mecanismo que opera a distinção entre as identidades (Woodward, 2000). Deve haver sempre, portanto, a possibilidade real de uma convergência de sentidos na formação interna dos lugares, ao mesmo tempo em que é igualmente necessário que os valores, sentidos e ações que delimitam e configuram os lugares possam ter uma existência externa aos lugares, como modo de atender às demandas de visibilidade e legitimidade públicas. Essa existência externa implicaria o deslocamento tático das sociabilidades internas que caracterizam certos lugares para outros espaços em que a visibilidade e confrontação públicas permitissem que tais sociabilidades se afirmassem. Em outras palavras, os lugares precisam de um espaço social que os transcenda e os questione. Esse espaço de confluência simbólica dos lugares e suas sociabilidades não é mais, como sugere Simmel (1986), um espaço de "relação intima", mas ele também não poderia ser um espaço completamente desprovido de sentido, teria no entanto que reter a capacidade pública e igualitária da coexistência conflitante da diferença. 
No Bairro do Recife, esse espaço de confluência ora se materializava nas fronteiras entre os lugares, ora nas zonas de passagens, ou mesmo quando ocorriam grandes eventos nas áreas físicas em que estavam circunscritos os lugares, cujas fronteiras se flexibilizavam em dias de festa. No entanto, foi o Marco Zero que se transformou no principal espaço de confluência de diferentes sociabilidades (relativas aos distintos lugares) do Bairro do Recife. Embora não fosse um lugar específico, o Marco nunca perdeu completamente seus significados efetivos, atuando potencialmente como um espaço aberto para múltiplas apropriações.

Para haver essa confluência, o espaço não deixa de ser alvo de disputas (espaciais, simbólicas e políticas), mas o mecanismo interativo muda substancialmente. A forma como os lugares e suas sociabilidades interagem publicamente não pode ser mais pela convergência de sentidos e experiências compartilhadas pelo entendimento, que os delimitam em sua configuração interna. Como precisam externalizar e afirmar pública e igualmente suas diferenças, podemos entender que as ações interativas acontecem mediante uma comunicabilidade política do desentendimento. A noção de desentendimento aqui utilizada se baseia na reflexão desenvolvida por Rancière (1996). Por "desentendimento", entende o autor "um tipo determinado de situação da palavra: aquela em que um dos interlocutores ao mesmo tempo entende e não entende o que diz o outro" (Rancière, 1996: 11). O "desentendimento" não se confunde com falta de conhecimento ou mal entendido, mas implica a existência de concepções discursivas diferentes sobre uma mesma coisa:

O desentendimento não é o conflito entre aquele que diz branco e aquele que diz preto. É o conflito entre aquele que diz branco e aquele que diz branco mas não entende a mesma coisa, ou não entende de modo nenhum que o outro diz a mesma coisa com o nome de brancura. [...] Os casos de desentendimento são aqueles em que a disputa sobre o que quer dizer falar constitui a própria racionalidade da situação da palavra. Os interlocutores entendem e não entendem a mesma coisa nas mesmas palavras. (Rancière, 1996: 11-12)

Essa noção de "desentendimento" tem, contudo, uma aparente contradição para a sua aplicabilidade no argumento que estou defendendo. Se o "desentendimento" pressupõe que os interlocutores estejam falando de fato de uma mesma coisa, mas que não a entendem da mesma forma, como explicar situações em que os interlocutores estariam de fato falando de coisas diferentes? Adequando essa questão à problemática aqui tratada: as diferenças que distinguem os lugares devem apenas ser entendidas como discordâncias sobre significantes ou devem também ser compreendidas 
como dissensões de significados? Esta aparente contradição se desfaz quando a noção de "desentendimento", sugerida por Rancière, é tomada em sua essência argumentativa: ela se refere aos mecanismos narrativos da política e da expressão social da discordância. O “desentendimento", desse modo, "designa o outro como aquele com o qual está em debate não somente o conflito de interesses, como também a própria situação dos interlocutores como seres falantes" (Rancière, 1996: 59). Recolocando o debate em torno da formação dos lugares, é possível dizer que uma comunicabilidade política do desentendimento, portanto, não apenas levaria em consideração as diferenças que demarcam os lugares, como o modo com que as suas sociabilidades constitutivas buscam formas públicas de reconhecimento através da contraposição a outros lugares.

Finalmente, embora o conceito de "desentendimento" seja utilizado por Rancière para designar, predominantemente, formas de articular a fala como racionalidade da palavra, a noção permite um uso mais abrangente, quando relacionada às práticas singulares da demarcação de lugares: "o desentendimento não diz respeito apenas às palavras. Incide geralmente sobre a própria situação dos que falam" (Rancière, 1996: 13). Os processos sociais que atribuem sentidos distintos a certas configurações socioespaciais não se distinguem uns dos outros por mero desconhecimento, mas exatamente por serem portadores de concepções diferentes sobre o que representa um espaço da cidade ou de um patrimônio cultural selecionado como representativo de uma tradição. A polissemia dos espaços urbanos e seus lugares representa, assim, uma forma política de desentendimento, manifestada pelos usos e contra-usos que espacializam a diferença. Esses espaços sociais de convergência de lugares, que comportam contextos de comunicabilidades políticas de desentendimentos, devem apresentar demarcações simbólicas mais flexíveis do que os territórios da subjetivação, mesmo que continuem subjetivados. Precisam, ao mesmo tempo, de possibilitar a subjetivação singular dos grupos, como também uma convergência mínima de sentidos coletivos, para que seja o espaço escolhido para a coexistência pública do dissenso e para a afirmação da diferença. Quanto mais esses espaços permitirem apropriações simbólicas diversificadas, mais eles terão sua potencialidade política e simbólica distendida, para que possam sediar as práticas de uma comunicabilidade política do desentendimento.

\section{Dos lugares ao espaço público}

Uma primeira sugestão analítica, para entender a natureza pública da vida urbana contemporânea, decorrente do caso do Bairro do Recife, é que não se tome o espaço público como dado. Ele não antecede ações e espaços, mas 
se constitui no curso dessas ações que atribuem sentido e criam lugares nos espaços da cidade. Uma das principais conseqüências dessa premissa seria a necessidade de desmembrar as categorias analíticas do debate sobre o possível esvaziamento do "espaço público". Parte das reflexões em torno do conceito de espaço público não se refere a uma única problemática. Diferentes abordagens tratam o tema com pelo menos três distintas conotações: como espaço urbano aberto de propriedade pública do Estado (Public Property); como espaço-signo das relações entre representações e poder que estruturam paisagens urbanas (Semiotic Space); e como esfera pública (Public Sphere), na qual os indivíduos como cidadãos engajados politicamente podem ver e ser vistos e se deparam com formas de solidariedade social (Gulick, 1998: 136).

No Brasil, o debate contemporâneo sobre "espaço público" retoma a crítica social como princípio analítico, para reafirmar a necessidade da constituição desses "espaços" como instâncias nas quais os direitos sociais possam ser reconhecidos, numa perspectiva em que a cidadania pressupõe a existência de uma sociabilidade baseada no reconhecimento dos diferentes valores e interesses da sociedade. Vários autores têm destacado justamente essas dimensões conceituais que articulam a noção de cidadania à existência dos espaços de sociabilidade pública, em contextos de democratização. Seja tomando o "espaço público" como esfera - enquanto "arena" ou "cenário" de debate, visibilidade e negociação - ou como espaço urbano, a discussão no Brasil retoma os grandes temas relativos ao caráter emancipatório da vida pública e à permanente interpenetração do público e do privado, remetendo à questão da existência de um padrão de civilidade que supere a miséria, a exclusão, o autoritarismo. O principal foco das abordagens que tratam o "espaço público" como esfera pública recai nas formas de participação política e organização da sociedade civil no interior do debate sobre democracia e construção da cidadania (Paoli, 1989; Telles, 1992; Costa, 1997; Paoli e Telles, 1998; Dagnino, 1998; Oliveira, 1999).

De forma semelhante, as análises que utilizam o termo "espaço público" como espaço urbano desenvolvem, na outra ponta do mesmo debate, a mesma angulação analítica em torno dos temas que têm marcado a face excludente da formação social brasileira: enfocando a dimensão espacial da desigualdade social, essas análises recuperam o sentido de lugar e a dimensão pública do espaço urbano, traduzidos nas distintas formas de ocupação dos espaços da cidade, na construção dos territórios urbanos e dos lugares políticos que expressam as demandas de cidadania e pertencimento (Arantes, A. A., 1997b e 2000; Arantes, O., 1993; Caldeira, 1997; Magnani, 1998; Orlandi, 1999; Peixoto, 1999). 
Ainda que seja possível tomar como complementares as noções de esfera pública e espaço urbano, creio ser necessário, contudo, apontar certas características que qualificam uma determinada rua como espaço público. A idéia de uma rua como "espaço complexo da cidadania" pressupõe que o espaço urbano seja não apenas uma "arena" - onde diferentes interesses tornam-se públicos - mas também que possa estruturar as próprias demandas que a cidadania reclama. Neste caso, entende-se que uma noção de espaço público requer, para qualificar como públicos determinados espaços urbanos da vida contemporânea, uma inserção conceitual de mão dupla entre espaço e sociabilidade pública. Implica, portanto, relacionar dois processos interdependentes, que concorrem simultaneamente para uma única direção: a construção social do espaço, enquanto produto e produtor de práticas sociais; e a construção espacial da sociabilidade pública, enquanto produto e produtor das espacializações da vida social.

Abordagens clássicas, como as de Hannah Arendt, tratam dessa dupla inserção de modo diferenciado. Para Arendt, as experiências públicas compartilhadas num "mundo comum" são constitutivas da noção de vida pública. A esfera pública é muito mais do que o local de visibilidade do real: é o local da "excelência humana", na medida em que permite ao homem se conhecer e firmar sua existência, superando a "privação" de não poder "realizar algo mais permanente do que a própria vida". O "público", acrescenta, é primeiramente o que "pode ser visto e ouvido por todos" (Arendt, 1987: 67).

A análise de Sennett (1998) sobre a substituição da cultura pública pela ideologia da intimidade permite tematizar outros aspectos da questão. Apesar de fazer uma crítica à sociedade intimista e defender abertamente os usos públicos da cidade, Sennett não esclarece se o que chama de "espaço público morto" é causa ou conseqüência da territorialização do espaço urbano, que, na sua análise, culmina na "atomização" das cidades. Sennett afirma, inicialmente, que a impessoalidade da vida pública é uma das razões pela qual os indivíduos se refugiam nos territórios pessoais ou comunidades destrutivas (Sennett, 1998: 29). Mas, em seguida, afirma que a formação da Gemeinschaft esvaziou o espaço público (Sennett, 1998: 320). O problema é que somente seria possível entender o isolamento social como conseqüência, na forma das comunidades destrutivas, se considerássemos a possibilidade de existência anterior de um espaço público, mesmo "morto" e sem uma cultura da vida pública.

Em que sentido é possível falar da existência de um espaço público sem cultura pública, sem interações, apenas marcado pelo isolamento, onde o temor de uma vida impessoal esvazia a cidade e tiraniza a intimidade na 
forma de "celebração dos guetos", da retribalização das relações sociais e da rejeição do desconhecido como intruso? Um espaço desprovido de interações (conflituosas ou não) continua sendo um espaço público ou se torna apenas um espaço urbano atomizado ${ }^{5}$ Essa distinção não é, mais uma vez, apenas um preciosismo conceitual. O diagnóstico de Sennett tem a pretensão de generalidade: não se refere a contextos específicos, ainda que trate indiretamente de aspectos da vida londrina e nova-iorquina, mas fala de um suposto "declínio do homem público". Com Sennett não é possível qualificar quando um espaço urbano pode se tornar (ou deixar de sê-lo) espaço público. Por permitir que se denomine qualquer espaço urbano de espaço público (morto ou não) e que se continue a chamá-lo assim mesmo quando inexistem formas de interação pública, o esquema analítico de Sennett não oferece uma distinção clara entre espaços urbanos que podem ser potencialmente espaços públicos e outros que têm poucas chances de o virem a ser, a exemplo das ruas urbanas que são "privatizadas" para dar acesso exclusivo aos seus moradores, de vias ou locais "públicos" que por falta de infraestrutura são subutilizados ou mesmo de certas vias ou logradouros urbanos como anéis viários, pontes e viadutos.

Enquanto a noção de esfera pública sugere uma predominância da ação sobre o espaço, a noção de espaço urbano opera justamente ao contrário. Mas não será demais lembrar que em uma rua, a despeito de ter fluxo contínuo de pessoas em movimento, a ausência de ações voltadas à interação pública de diferentes pontos de vista faz com que inexista uma qualificação política que possa distingui-la como espaço público. No entanto, permanece válido pensar a rua como um segmento do espaço urbano potencialmente voltado às experiências públicas, em contraposição à esfera da vida privada, ainda que cada vez mais essas duas esferas se interpenetrem. A separação entre esses espaços da vida social tem cada vez mais apresentado áreas de intersecção que redesenham as fronteiras entre o público e o privado, cujas reconfigurações elaboram, como sugere Arantes (2000), "referenciais espaço-temporais flexíveis". A rua é antes, pelo menos por definição, um espaço urbano de caráter predominantemente público, no sentido de propriedade pública do Estado (Gulick, 1998). Nela podem ser instituídos o que Holston (1993) chamou de "sistema de espaços públicos", ao se referir à supressão de ruas e esquinas da moderna arquitetura de Brasília, que

\footnotetext{
${ }^{5}$ Sobre esse ponto, Sennett exemplifica sua idéia a partir do pátio "público" do Brunswick Centre, em Londres, cujo traçado arquitetônico teria como função isolar o prédio dos transeuntes da rua, inibindo qualquer forma de interação entre as pessoas. No limite da sua crítica aos espaços públicos de passagem, Sennett chega a comparar a rua urbana ao espaço público de passagem por excelência, ainda que nela não exista sobrevida de cultura pública (Sennett, 1998: 26-28).
} 
elimina esses "pontos de convivência social", cuja dimensão cotidiana se expressa (também) nas relações primárias de vizinhança.

A existência per se de ruas e esquinas movimentadas não é, assim, condição suficiente, embora necessária, para instituir um espaço público. A obstrução privada das ruas pode inibir a construção de seu sentido público, mas a sua desobstrução não garante necessariamente que nela se desenvolvam usos e práticas capazes de diferenciá-las como espaço público. Seguindo o mesmo raciocínio, o esvaziamento temporário de uma rua também não significaria a ausência dessa característica pública, mas tão somente a suspensão de certas sociabilidades em alguns dias ou horários. Penso, nesse caso, naquelas áreas típicas das grandes concentrações públicas, como o vale do Anhangabaú, em São Paulo, ou a Pracinha do Diário, em Recife, que em dias "normais" parecem apenas uma via pública qualquer, mas retêm múltiplas significações para a população, por representarem lugares políticos. É nesse sentido que, ao analisar as transformações do espaço público paulistano, Arantes (2000) enfoca as dimensões políticas e culturais da produção social do espaço, ao argumentar, com Schechner (1993), que as manifestações de uma sociabilidade pública não eclodem em qualquer rua, mas em certos espaços que têm significações para os atores envolvidos. Mais do que um simples "cenário" para determinadas práticas sociais, o espaço torna-se reflexivo: ganha significação pelas ações e lhes é constitutivo.

A circunstancial relação causal entre esfera pública e espaço não torna menos plausível a premissa contrária: o espaço pode ser, em certos casos, mais do que uma simples contingência para a estruturação das sociabilidades públicas. O espaço pode vir a ser, nos casos em que os agentes se reconhecem pelas significados comuns por eles atribuídos, em fator de inteligibilidade da constituição da própria esfera pública, na medida em que certas dimensões espaço-temporais incidem sobre os motivos das ações públicas. Não por acaso, o Largo do Marco Zero no Recife foi também o local que passou a abrigar atos públicos e manifestações políticas. Além de ter se tornado, inclusive em decorrência de sua escala, um espaço propício a aglomerações urbanas, o Largo retinha um sentido comum para a Cidade do Recife: era o seu marco zero, ponto de origem, de chegada e de partida. Talvez essa reminiscência comum tenha sido a única sobrevida de uma experiência mais amplamente compartilhada de entendimento (típica dos lugares) que se manteve no Largo. E, em decorrência dessa eficácia genérica, o Largo possibilitou que a convergência de diferentes sociabilidades traduzisse esse entendimento em dissensões públicas (típica dos espaços públicos), diferenciando os lugares e o espaço público - duas categorias que igualmente pressupõem uma existência reflexiva entre espaço e ação. 
Uma noção de espaço público, construída a partir das interfaces entre os conceitos de esfera pública (da qual retira a categoria ação) e de espaço urbano (do qual retém a sua referência espacial), necessitaria contemplar as relações de reciprocidade causal entre a construção social do espaço e a espacialização das ações sociais. Da relação entre espaço e ação, as práticas interativas (ações) atribuem sentidos aos lugares (espaço), que por sua vez contribuem para a estruturação dessas ações, promovendo a confluência entre o espaço urbano e a esfera pública, construtos dos quais a noção de espaço público retira suas principais categorias. Embora se constitua no espaço urbano, é possível entender o espaço público como algo que ultrapassa a rua; como um conjunto de práticas que se estruturam num certo lugar. Enquanto espaço social, um espaço público não existe a priori apenas como rua (que, ao contrário, é sempre rua, vazia ou não), mas se estrutura pela presença de ações que lhe atribuem sentidos.

Embora distintas, as noções de espaço urbano e esfera pública têm interfaces: ainda que uma esfera pública não se limite a uma determinada configuração física (quando mediática ou virtual, por exemplo), pode se estruturar num espaço urbano específico, como uma rua ou uma praça. Mesmo não sendo per se um local de interações e reivindicações públicas (sejam reivindicações de validade, ideológicas ou instrumentais), o espaço urbano (propriedade pública) pode vir a constituir-se em uma esfera pública quando ao seu espaço são atribuídos sentidos (tornando-o lugar) para as reivindicações em curso. Nesse caso, entende-se que determinadas reivindicações públicas guardam relações com os lugares sociais nos quais se estruturam. Uma noção de espaço público, portanto, que não considere as práticas interativas entre os agentes envolvidos na construção social do seu espaço estaria simplesmente se referindo ao espaço urbano. Assim como a noção que prescinde de uma referência espacial para as ações interativas entre os agentes poderia ser chamada de esfera pública, na medida em que, como acertadamente sublinha Sérgio Costa (2002), em seu As Cores de Ercília:

[...] malgrado a metáfora espacial que sugere, equivocadamente, a existência de uma localização específica na topografia social, a esfera pública diz respeito mais propriamente a um contexto de relações difuso no qual se concretizam e se condensam intercâmbios comunicativos gerados em diferentes campos da vida social. (Costa, 2002: 12)

Um dos caminhos para a compreensão da natureza dos espaços públicos em áreas enobrecidas como a do Bairro do Recife consiste em evitar a sobreposição desses termos, como ocorre muitas vezes nos estudos de 
urbanismo, ao se chamar de "espaço público aberto" o que seria simplesmente uma propriedade pública. Parte dos espaços urbanos em sítios históricos enobrecidos não se constitui em espaço público, embora continue a ser logradouro público. Sem a presença de agentes e de suas respectivas comunicabilidades políticas, as ruas continuam a ser simples espaços urbanos. A distinção entre os conceitos não ajuda apenas a evitar sobreposição de termos, também orienta reflexões sobre a natureza pública dos espaços urbanos. É possível que Hannah Arendt, que também discorreu sobre a gênese da moderna concepção de intimidade enquanto fuga do mundo, entendesse a preocupação central de Sennett sobre as tiranias da intimidade. O que talvez não seja tão compreensível seja o obituário de Sennett, baseado na fragmentação dos espaços urbanos. Ainda que argumente que a tirania da intimidade promove uma subversão das relações entre o público e o privado (transformando em pessoal um espaço que seria reservado ao desconhecido), seria possível contra-argumentar que essa tensão entre o público e o privado sempre foi constitutiva da formação do espaço público, como ressaltam Arendt (1987) e Habermas $(1996,1997)$ ao analisarem as transformações da esfera pública em função da "desprivatização" da família. É desse constante desafio de diferenciar-se das condutas íntimas, mas às vezes de confundir-se com elas, que as ações públicas se qualificam como políticas. Pela invasão ou evasão da privacidade, a esfera íntima sempre esteve à espreita da vida pública, seja para legitimar-se, tornar-se visível ou para apropriá-la. De modo inverso, a cultura pública também sempre tentou moldar as condutas íntimas, segundo os ditames de cada época e lugar. Por fim, é possível sugerir que mesmo essa fragmentação da cultura urbana em guetos e nichos não elimina necessariamente o sentido púbico da vida urbana. No Bairro do Recife, apenas aqueles espaços que foram capazes de abrigar as disjuntivas de interesses e opiniões poderiam ser considerados espaços públicos. Para se tornar locus da igualdade de direitos e da liberdade política, o espaço público deve suportar também as assimetrias de fala e participação, que refletem muitas vezes as desiguais formas de inserção social dos agentes envolvidos. Ao contrário de perder sua prerrogativa política com o litígio, o espaço público pode se constituir exatamente no ponto onde as discordâncias afloram.

Um espaço público, como categoria sociológica da vida política da cidade, estrutura-se pela presença de ações que atribuem sentidos a certos espaços urbanos. A dimensão propriamente conflitante é, pois, inerente à estruturação do espaço público, na medida em que ele pode ser traduzido como o espaço do discurso, da ação política e da diferenciação. Se está correto esse pressuposto teórico, é possível falar da existência ou 
não de espaços públicos em áreas de gentrification a partir das disputas pela construção dos diferentes lugares sociais, que nesses espaços podem se estruturar como forma de externar as possibilidades de contestação e discordância. A fragmentação do espaço urbano em diferentes lugares no contexto da cultura urbana contemporânea não elimina o sentido público da vida urbana, mas o modifica na proporção em que essa cartografia pública se complexifica pela exacerbação da diferença.

\section{Referências bibliográficas}

AD/DIPER - Agência de Desenvolvimento Econômico do Estado de Pernambuco (1992), Plano de Revitalização - Bairro do Recife. Recife: Planejamento Urbano e Economia. Vol.1,37-39.

Appadurai, Arjun (1986), The Social Life of Things: Commodities in Cultural Perspective. Cambridge: Cambridge University Press.

Arantes, Antonio A. (1997a), "Patrimônio cultural e nação", in Angela M. C. Araújo, Trabalho, cultura e cidadania. São Paulo: Scritta.

Arantes, Antonio A. (1997b), "A guerra dos lugares: Fronteiras simbólicas e liminaridade no espaço urbano de São Paulo”, in Carlos Fortuna (org.), Cidade, cultura e globalização. Ensaios de sociologia. Oeiras: Celta Editora.

Arantes, Antonio A. (2000), Paisagens paulistanas: Transformações do espaço público. Campinas: Ed. Unicamp.

Arantes, Otília (1993), O lugar da arquitetura depois dos modernos. São Paulo: EDUSP/ Studio Nobel.

Arendt, Hannah (1987), A condição bumana. Rio de Janeiro: Forense Universitária.

Augé, Marc (1994), Não-lugares: Introdução a uma antropologia da supermodernidade. Campinas: Papirus.

Benjamin, Walter (1997), "Paris, capital do século XIX", in Carlos Fortuna (org.). Cidade, cultura e globalização. Ensaios de sociologia. Oeiras: Celta Editora.

Caldeira, Teresa (1997), "Enclaves fortificados: A nova segregação urbana", Novos Estudos, Cebrap, 47.

Castells, Manuel (1999), A sociedade em rede. Vol. 1. São Paulo: Paz e Terra.

Costa, Sérgio (1997), "Contextos da construção do espaço público no Brasil", Novos Estudos do Cebrap, 47.

Costa, Sérgio (2002), As cores de Ercília. Belo Horizonte: Editora UFMG.

Dagnino, Evelina (1998), "Culture, Citizenship and Democracy: Changing Discourses and Practices of the Latin American Left", in S. Alvarez et al. (orgs.), Cultures of Politics, Politics of Cultures. Oxford: Westview Press.

Featherstone, Mike (1995), Cultura de consumo e pós-modernismo. São Paulo: Studio Nobel. 
Fortuna, Carlos (1997), "Destradicionalização e imagem da cidade: O caso de Évora”, in Carlos Fortuna (org.), Cidade, cultura e globalização. Ensaios de sociologia. Oeiras: Celta Editora.

Guattari, Félix (1985), "Espaço e poder: A criação de territórios na cidade”, Espaço e Debates, 16.

Gulick, John (1998), “The Disappearance of Public Space: An Ecological Marxist and Lefebvrian Approach”, in L. Andrew; J. M. Smith (org.), The Production of Public Space. New York: Rowman \& Littlefield Publishers.

Gupta, Akhil; Ferguson, James (1992), "Beyond Culture: Space, Identity and the Politics of Difference", Cultural Antbropology, 7(1).

Habermas, Jürgen (1996), The Structural Transformation of the Public Sphere. Cambridge, Massachusetts: The MIT Press.

Habermas, Jürgen (1997), "The Public Sphere”, in R. Goodin; P. Pettit (orgs.), Contemporary Political Philosophy. Cambridge, Massachusetts: Blackwell Publishers.

Harvey, David (1992), Condição pós-moderna. São Paulo: Loyola.

Holston, James (1993), A cidade modernista. São Paulo: Companhia das Letras.

Kilian, Ted (1998), "Public and Private, Power and Space", in L. Andrew; J. M. Smith (orgs.), The Production of Public Space. New York: Rowman \& Littlefield Publishers.

Leite, Rogério Proença (2002), "Contra-usos e espaço público: Notas sobre a construção social dos lugares na Manguetowm”, Revista Brasileira de Ciências Sociais, 49.

Leite, Rogério Proença (2007), Contra-usos da cidade: Lugares e espaço público na experiência urbana contemporânea. Campinas/São Cristóvão: Editora Unicamp/Ed.UFS [2 ${ }^{\mathrm{a}} \mathrm{Ed}$.].

Magnani, José Guilherme C. (1998), Festa no pedaço: Cultura popular e lazer na cidade. São Paulo: Hucitec/Unesp.

Martín-Barbero, Jésus (2000), "Dislocaciones del tiempo y nuevas topografias de la memoria”, in H. B. Hollanda; B. Resende (orgs.), Artelatina: cultura, globalização e identidades contemporâneas. Rio de Janeiro: Aeroplano Editora.

Oliveira, Francisco de (1999), "Privatização do público, destituição da fala e anulação da política: O totalitarismo neoliberal”, in F. Oliveira; M. C. Paoli (orgs.), Os sentidos da democracia. Políticas do dissenso e hegemonia global. Petrópolis: Vozes.

Orlandi, Eni P. (1999), "N/O limiar da cidade", Rua: Revista do Núcleo de Desenvolvimento da Criatividade, Unicamp, Edição Especial.

Paoli, Maria Célia (1989), "Trabalhadores e cidadania: Experiência do mundo público da história do Brasil moderno", Estudos Avançados, 3(7).

Paoli, Maria Célia; Telles, Vera (1998), "Social Rights: Conflicts and Negotiations in Contemporary Brazil", in S. Alvarez et al. (orgs.), Cultures of Politcs, Politcs of Cultures. Oxford: Westview Press.

Peixoto, Nelson Brissac (1999), "Intervenções urbanas”, Rua: Revista do Núcleo de Desenvolvimento da Criatividade, Unicamp, Edição Especial. 
Rancière, Jacques (1996), O desentendimento. São Paulo: Editora 34.

Schechner, Richard (1993), The Future of Ritual. London/New York: Routledge.

Schorske, Carl E. (1990), Viena fin-de-siècle. Política e cultura. São Paulo: Companhia das Letras.

Sennett, Richard (1998), O declínio do homem público. São Paulo: Companhia das Letras.

Simmel, Georg (1986), Sociologia 2: Estudios sobre las formas de socialización. Madri: Alianza Universidad.

Smith, Neil (1996), The New Urban Frontier: Gentrification and Revanchist City. London/New York: Routledge.

Telles, Vera (1992), A cidadania inexistente: Incivilidade e pobreza. Tese de Doutorado, São Paulo: Departamento de Sociologia, USP.

Wooddward, Kayhyn (2000), "Identidade e diferença: Uma introdução teórica e conceitual", in Tadeu Tomaz Silva (org.), Identidade e diferença: A perspectiva dos estudos culturais. Petrópolis: Vozes.

Zukin, Sharon (1995), The Cultures of Cities. Cambridge, Massachussetts: Blackweell.

Zukin, Sharon (2000), "Paisagens urbanas pós-modernas: Mapeando cultura e poder", in António Arantes (org.), O espaço da diferença. Campinas: Papirus. 